\title{
System performance indicators of regional economic security
}

\author{
Yuliya Lysenko ${ }^{1}$, and Janna Zelenskaya ${ }^{1{ }^{*}}$ \\ ${ }^{1}$ Higher School of Economics and Management, South Ural State University (NIU), Chelyabinsk, Russia
}

\begin{abstract}
The article presents the scientific analysis of the elements of the developed methods for constructing effective system of the regional economic security, which is important for the national security in the whole. The purposes of economic security management, which determines the ways of applying the proposed methods, are outlined. The notion of "regional system of providing economic security" is introduced and the objects of providing security are identified. The relevance of creating the direct and reversed data streams is clarified with federal executive bodies, especially with fiscal and law enforcement, and the development of the forms of interaction with social groups and economic agents is presented. The socio-economic indicators, which serve as criteria for effectiveness of the economic security system, are stressed. All the elements of the given system integrated into the system of management of socio-economic region development have block representation. The article emphasizes the necessity of identifying specific weight value of each constituent element of security during the complex estimation. Keywords - economic security, effective system, interconnected components of the system, the regional program, the public demands, minimizing internal and external threats.
\end{abstract}

The economic development under the influence of market mechanisms of the Russian integration into the world economic relations has identified the economic security which is the basis of national and state interests as the most important functions of the state. This is due to the fact that the market economy is not able to perform this function, and the economic interests of economic entities may be contradicted to the national interest, because in their activity they, first of all, pursue income maximizing, maximum exploitation of natural, industrial and labor resources $[1,2]$.

The purpose of economic security management is to counteract the threats to prevent their transforming and damaging the regional social and economic systems. Achieving this goal is based on the position of the National Security Concept of the Russian Federation and state economic security strategy should be provided by developed strategy for socio-economic development of regions based on the general concept of long-term socioeconomic development of the Russian Federation. All above mentioned is aimed at carrying out targeted regional policy.

This is due to the fact that the national interests of the country, its holistic territorial socio-economic development priority are based on the stable operation of the regions. So it is urgent to construct an effective system to ensure the economic security of the region, which involves the creation and implementation of opportunities focused on the impact of internal and external threats for the regional market [3, 4].

In modern conditions of territorial differences in level approach indicators of economic security of the country related to the uneven social development of the
RF subjects, peculiarities of their economies functioning and the allocation of productive forces on their territories. The degree of economic security areas is affected by the quality of human potential, the level of development of innovative processes (which, unfortunately, in some regions, are very low), the investment climate dynamics and other factors.

The necessity of an effective system of regional economic security development in the aspect of national security of the country determines the significance of the analysis of the key indicators of regional development, assessment and identification of differences in terms of economic security level between the individual regions. It is necessary to conduct a comprehensive assessment of the regional economic security, allowing to identify the main directions of the regional policy in the aspect of economic security [5].

The aim of the research in this article is to review the constituent elements of the method of constructing an effective system to ensure the regional economic security such as objects, subjects, factors, criteria and indicators and the relationship between them.

Federal authorities provide protection only on the largest and most terrible threats. And the population of the country is subjected to a much wider circle of threats in their daily lives, many of which are territorial in nature. Measures to detect and locate such problems can be most effectively carried out by public authorities of the RF subjects, due to their presence in the territory and its proximity to the population.

Before revealing the economic security indicators, it is necessary to propose such notion as a "regional system of economic security", which is recognised as a set of

\footnotetext{
Corresponding author: zhalenz@yandex.ru
} 
conditions and factors, institutions and mechanisms for protecting the regional economic interests, improvement of the scope of the population. Economic security on the regional level is provided by the identification and prevention the internal threats of action in various spheres of regional life [6, 7].

Thus the objects of the regional economic security are the territory of the Federation subject, the population and everything related to the economy, located in the territory, including production facilities, infrastructure, natural and other resources.

Under current conditions in Russia the necessity of modern mechanisms and instruments development, priority associated with the economic policies development directed to improving the population's quality of life, is defined as a priority to ensure the economic security of the country regions. Detailed regional economic security programs must have a clear social orientation. The quality of life in this aspect is the main criterion for the safety of social and economic development of the region. In accordance with the selected model of improving the standard of living of the population in the region development policies should be directed to the population growth, the growth of its real income, improve their living conditions.

So, one of the main criteria that characterizes the region interests in the sphere of security and acceptable for the majority of the population quality of life, includes the following:

- the growth of real incomes of the population;

- an increase in natural population growth;

- improvement of housing and infrastructure conditions.

As a basis for the construction of the region economic security a common approach to the formation of a mechanism to ensure the economic security of the country was taken.

As a result, the economic security system, adapted to the specific regional problems, is proposed to include the following blocks:

- the organizational structure as a system of legislative, executive and judicial powers, public or other organizations and associations;

- legal framework regulating relations in the sphere of economic security of the region;

- priorities of ensuring economic security of the region in the context of long-term socio-economic development and national security of Russia in the economic sphere;

- internal threats in the economic field, affecting the standard of living;

- housekeeper condition monitoring system to detect and predict threats to economic security;

- tools for assessing the level of regional security through economic security indicators, their threshold values;

- a combination of organizational, legal and economic measures to prevent threats, ensure economic security.

A method for constructing an effective system to ensure the regional economic security is reflected in the form of the system of the elements and relationships between them (Fig. 1).

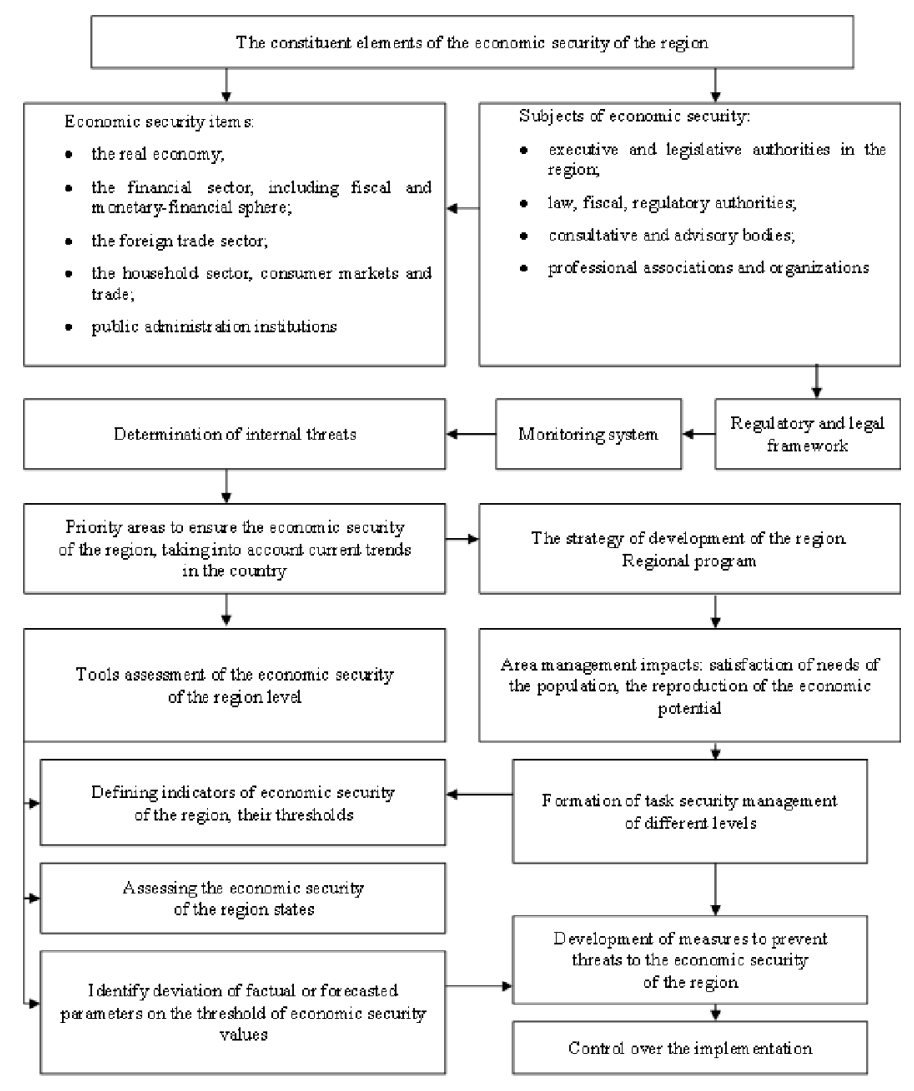

Fig 1. The system of the regional economic security.

The key factor determining the methodological approaches to the construction of an effective system of economic security is the integration of this system into the management of regional socio-economic development, which requires [8]:

- forming permanently stable relations with all the structural units of the legislative and executive authorities of the Federation authorities, professional associations and organizations engaged in control functions;

- attracting experts to solve specific problems of assessment, diagnosis and forecasting of social and economic processes and phenomena;

- creation of the direct and reverse data stream with federal executive bodies, especially fiscal and law enforcement;

- the development of forms of interaction with social groups and economic entities.

Being the subject of economic security, legislative regional authorities form the institutional environment through the development of legal acts, the regional programs and standards, a set of other tools and methods to ensure the economic security of the region. This requires regulatory legal space of the Federation, a mandatory feature which must be coherence and consistency of the provisions of the documents adopted in the particular priority of preserving and improving the level of economic security of the region.

To minimize the possibility of negative impacts from the introduction and not the introduction of norms and regulations, a full role in the structure of the subjects of 
management is assigned to advisory and advisory bodies, as well as to professional associations and organizations.

The starting point for development of policies and programs to ensure the regional economic security is a monitoring and data analysis system. It covers various aspects of life in the region and is aimed at identifying threats to economic security. Regional authorities should always use a variety of tools to analyze associated with the definition of real and potential threats. At the same time a central place in the monitoring system should be allocated to internal threats, taking into account specific regional focus of policies related to the solution of problems of social protection and raising the standard of living of the population of the region [9].

The assessment criteria is population needs, which vary depending on income, membership of social, national and ethnic groups, and other factors. Therefore, at the regional level it is necessary to fix a reference liststandard services, products and activities, reflecting at least some basic biological and social needs, as well as civil rights, material and spiritual goods, guaranteed by the state. The challenge of meeting these needs is the responsibility of government of the Federation.

Each specific area has its own peculiarities in the aspect of economic security and its maintenance, so there is a necessity of the system development of indicators and parameters that are taken into account by regional specificities. It should be noted that the indicators existed at the moment, are related to federal authorities. At the same time, when taking into account the specific characteristics of the regional problems it is important to work out a clear methodology for containing the regional safety performance, purpose of use which can be summarized as follows:

- assess the crisis and the threat of their occurrence in the socio-economic sphere of the region;

- assess the impact of crisis situations in the region to the national economic security of the subject of the Russian Federation and the country as a whole;

- develop and validate software and targeted activities to ensure economic security of the region;

- to establish an effective economic security of the region management system.

The main requirements to the system of socioeconomic development indicators (SEPR) regions must include the following:

- the relationship between general methods of analysis SEPR region system and the indicators used on the federal and branch levels;

- the compatibility of regional security with the existing indicators in the state accounting system, statistics, analysis and forecasting;

- optimal inventory SEPR for the analysis and display of the actual situation in the region;

- simplicity and clarity as to the consistency of the results of the analysis of the status quo;

- compliance SEPR one time period when describing aspects of the socio-economic situation;

- the presence of the possibility of using these indicators for the regular monitoring and forecasting of the factors affecting the level of economic security of the region.

In formulating the purpose of the analysis of the economic security of the region on the basis of certain indicators, the following groups of objects:

- indicators incomes of the population (compared with the average cost of living and minimum wages and pensions, the different levels of income in different sectors of the population, employment dynamics and others.);

- demographic indicators (birth and death rates, life expectancy, incidence of disease, and others.);

- indicators of the state of housing and communal services (number of infrastructure projects for 10000 people, moral and physical deterioration of assets, technological accidents, etc.).

According to the set of indicators analyzes the state of the region, on the basis of which, with the existing appropriate, covers the development of the crisis exit scenarios, depending on the chosen approach to the assessment of internal threats. This technique is versatile, and can in principle be selected such a set of indicators that would fully satisfy the safety development of specific sectors of the region concept.

Along with the problem of choosing the optimal list of indicators to measure economic security urgent question of determining the specific gravity with a comprehensive assessment of each of the constituent elements of security. If we consider the figures depend on each other in a linear or non-linear dependence, it could mean that the information system contains data that distort the results of the analysis and, as a consequence, the prediction results, which requires multiple analysis of the totality of the set parameters.

The use of modern information technology makes it possible to simulate the control system, taking into account not only the input data, but also the structure and data communications in a single economic process. Also there is the possibility to simulate the control system on the basis of the various options, taking into account the non-linear nature of the relationship, erroneous input. In any case, the introduction of amendments to the original data needs to be able to quickly change further refine ready model management process.

The key issue, the solution of which depends on the effectiveness of the development measures for the prevention of threats and damage assessment of their impact, is to determine the threshold values of economic security that can be called a response to the action of various factors risk. Important condition is that matching components of economic thresholds security parametric list of regions, reflecting the national interests of Russia as a whole. The composition of these thresholds should not be identical with the general list, as the economy of each individual region has its own specific characteristics that should be shown in the list, and the numerical characteristics of the threshold values of economic security.

The basis of the system of thresholds of economic security of the region are the basic provisions contained in the government's economic security strategy, 
developed and approved by the regions in consultation with the Ministry of Economic Development of the Russian Federation. At the same time finding all set of indicators within acceptable limits and compliance with the conditions for achieving certain performance is not to the detriment of others provides the highest degree of security [10-12].

It is important to emphasize that the most demonstrative and easy-to-use is considered to be a functional analysis of economic security, which aims to identify deficiencies and potential use of a number of measures that ensures each functional component of economic security of the territory as a whole. This type of analysis also helps to use the possibility to carry out an adjustment function to ensure economic security.

The procedure of analysis of the economic state of the region's security in the most optimal form can be represented as follows:

- determination of the composition, structure, adverse effects of each component in terms of the performance of the functions of economic security areas;

- separation of the objective and subjective elements;

- assessment of the likelihood and timing of the certain negative impacts, as well as the estimated amount of damage;

- the formation of a list of measures aimed at assessing the level of economic security and eliminating the impact of adverse impacts;

- assessment of the effectiveness of the measures taken in the aspect of neutralizing the negative effects of each component in terms of the running for the economic security functions;

- determining the causes of lack of effectiveness of the measures taken for the elimination of existing and prevention of possible negative effects, the definition of the persons responsible for the ineffective implementation of the measures taken;

- development of recommendations for the prevention and prevention of adverse effects;

- assessment of the value of each of the measures to rely on the elimination of negative impacts and the definition of responsible persons;

- definition of material, financial and other resources required to remedy it;

- development and adoption of legal documents governing the activities to eliminate prejudice and eliminate its consequences.

Single indicator, which characterizes the economic security risks associated with the fact that it assessed the situation in any area. This allows us to conclude the feasibility of using a system of indicators that allows realistically assessing the level of threat and getting an objective assessment. This objective of this type of assessment can be achieved by comparing the safety performance of a number of neighboring regions.

It is important not simply to evaluate the macroeconomic indicators, which are difficult to affect in an expeditious manner, but also to use indicators that are able to influence the authorities in both the strategic and the operational order, using different methods of influence.
If the value of economic security indicators in the individual territories is crucial, it is not always indicative of the crisis situation in the socio-economic area or separate areas. This suggests the need to implement management bodies of measures to surgery in order to change and eliminate dangerous trends, as well as reducing the threat level.

Timely decision-making on minimization of various threats at the federal state level is based on the creation of a list of indicators mandatory for the submission of reporting forms by regional authorities.

Thus, the need to ensure economic security determines the priorities of the regional administration. In this context, the measures taken to increase the gross regional product should be considered as a tool for improving the standard of living. The economic development programs are necessary to correlate target prospects with indicators of regional economic security. In turn, the economic security of the system should be integrated into the socio-economic development of the regional management system.

The work was financed under the Act 211 of the Government of the Russian Federation, contract no. 02.A03.21.0011.

\section{References}

1. State strategy of economic security of the Russian Federation Main provisions, 608 (1996)

2. V. Vasenkov, National security: theory, policy, strategy (NPO Module, 2000)

3. The concept of long-term socio-economic development of the Russian Federation until 2020, 1662-R (2008)

4. About bases of state regulation of foreign trade activity, 164-FZ (2003)

5. The national security strategy of the Russian Federation until 2020, 683 (2015)

6. On security, 390-FZ (2010)

7. S.Y. Glazyev, The Basis of economic security of the country: alternative reformation rate (1997)

8. N.P. Vashchekin, M.I. Dzliev, A.D. Ursul, The Security and sustainable development of Russia (MGUK, 1998)

9. G.S. Alimov, Formation of the organizationaleconomic mechanism of management of competitiveness of regions (by example of Central Federal district regions) (2012)

10. L. Abalkin, QE, 12, 48-59 (1994)

11. M. Alekperov, BIC, 1 (2000)

12. V.V. Vinogradov, The Russian Economy (Yurist, 2007) 